\title{
Role of organic matter, clay, and iron contents in the sorption of oxytetracycline on river sediments
}

\author{
Mahmood Mahdi Barbooti* \\ Assistant Professor of Environmental Chemistry, Department of Applied Sciences, University of Technology, Baghdad, Iraq
}

\begin{abstract}
Background: Oxytetracycline (OTC) is a widely-used antibiotic; metabolism studies indicate only partial assimilation of it inside the body. Traditional wastewater treatment plants cannot remove OTC, and this results in the release of considerable amounts of the drug into aquatic environments. There is much concern over the role of residual antibiotics in the development of new generations of bacteria with modified resistance to the antibiotics. The present work investigated the possibility of OTC sorption on river sediments.

Methods: Seven sediment samples were collected from various locations and depths of the Passaic River in New Jersey. The texture, clay, extractable iron, and organic matter contents of the sediments were determined. Pyrolysis-gas chromatography-mass spectrometric (Py GC-MS) analysis indicated the presence of 3 categories of organic materials: petroleum hydrocarbons, anthropogenic, and plant residual materials. The sediment samples were equilibrated with OTC solutions for 24 hours followed by centrifugation and syringe filtration. The residual OTC contents were determined by high performance liquid chromatography. Results: It appeared that $35 \%-60 \%$ fractions of OTC were retained by the sediments. The sorption capacity values of the sediments were correlated with clay content, organic matter content, and available iron. A poor correlation was found between adsorption capacity and clay content in the presence of organic matter and iron. Meanwhile, a relatively strong correlation was found between adsorption capacity with the iron, $\mathrm{R}^{2}=$ 0.7499 , and organic matter contents of the sediments, $\mathrm{R}^{2}=0.7899$. Thus, the sorption of OTC on sediments is governed by all constituents.

Conclusion: It was concluded that the antibiotic-sediment interaction is controlled mainly by the organic matter and iron contents.

Keywords: Oxytetracycline, sorption, Passaic River sediment, Organic matter, Pyrolysis gas chromatographymass spectrometry, Py GC-MS

Citation: Barbooti MM. Role of organic matter, clay, and iron contents in the sorption of oxytetracycline on river sediments. Environmental Health Engineering and Management Journal 2017; 4(2): 109-115. doi: 10.15171/EHEM.2017.15.
\end{abstract}

\section{Article History:}

Received: 18 November 2016

Accepted: 18 February 2017

ePublished: 12 March 2017

\section{Introduction}

The production and use of drugs are increasing worldwide. Antibiotics are among the most common medications used for human and veterinary treatments. As a result, when sewage sludge and manure are used as fertilizers on agricultural land, they are often contaminated with antibiotics (1). The fate of drugs and drug metabolites in the environment is of increasing concern around the globe. Studies have shown that a large percentage of consumed antibiotics is excreted without change (2) into the hydrosphere. Many researchers have detected various antibiotics in water samples (3). Sewage treatment plants do not remove residual antibiotics from wastewater (4), and this contributes to the risk of new generations of bacteria with modified resistance to antibiotics being created $(5,6)$. The fate of pharmaceuticals in the environment is not different from that of other organic chemicals such as pesticides (7). Antibiotics appear in the environment when sewage sludge, manure, and other organic additives are applied to soils. Residual antibiotics have been detected in soils in varying concentrations $(8,9)$. Oxytetracycline (OTC) is among the most frequently existing antibiotics in river sediments. A level of 0.52-2.68 $\mathrm{ng} \mathrm{g}^{-1}$ of OTC was found in Yangtze Estuary sediments (10). The highest antibiotic concentration, $4695 \mathrm{ng} \mathrm{g}^{-1}$ of OTC was found in estuarine sediment from Ziya New River (11).

Efforts worldwide are directed towards establishing methods to remove TC from water using various sorbents such as activated charcoals and clay minerals $(12,13)$. Clay minerals, like montmorillonite, are effective at removing them from water (14). The use of clay in sorption studies has provided useful insights into the fate of antibiotics in river sediment systems. Knowledge of persistence pollutants and their sorption behavior is crucial for the evaluation of the mobility (7). Bezza et al (15) investigated the significance of $\mathrm{pH}$, organic matter, and the presence 
of metal ions on the extent of adsorption of TC. The role and function of natural organic material in both aquatic and terrestrial environments is strongly related to nutrient availability for plants. It can also influence the physicochemical conditions of soil and sediments as well as their buffering and exchange capacities. These are relevant for the immobilization and mobilization of many environmental pollutants (16). Shareef and Ahmed (17) found that OTC strongly and preferentially adsorbs on the surface of local Iraqi soils through a bonding mechanism. Kasteel et al (18) reported that the sorption of antibiotics into soil was time-dependent and affected by $\mathrm{pH}$ with a higher sorption capacity for loamy sand. Li and Zhang (19) studied the effects of organic carbon (OC) content and particle size on the adsorption capacity of OTC on 2 marine sediments. They studied the kinetics and proved that diffusive mass transfer was the dominant mechanism of time-dependent adsorption of OTC; they also reported that its release from marine sediment was mildly hysteretic. For some antibiotics, like chlortetracycline, the sorption to sandy loam and clay is rapid; more than $95 \%$ of it is adsorbed within 10 minutes of contact. A comparable proportion of tylosin is adsorbed within 3 hours (20). During their study of OTC sorption on organic materials, MacKay and Canterbury (21) found that there was no detectable sorption on cellulose or lignin sorbents containing few metal-complexing ligand groups. The sorption to humic acid increased with Fe(III)-amended clean humic acid with $\mathrm{K}(\mathrm{d})$ values of $250000 \mathrm{~L} \mathrm{~kg}^{-1}$. They suggested the formation of ternary complexes with humic acid (organic matter), metals, and pharmaceutical ligand groups. This reflects the importance of organic matter as a sorbent phase in soils and sediments for pharmaceutical compounds. Jones et al (22) reported that the interaction of OTC with soil organic matter, clay minerals, and metal oxides accounts for the strong sorption of the antibiotic. Soil texture, iron oxide content, and cation exchange capacity (CEC) have the greatest influence on the extent of OTC sorption in soils with OC (22).

Recently, Kong et al (23) proved that, in addition to the permanent CEC, soils with relatively high illite content have a high OTC sorption capacity. However, the availability of sorbed OTC increases as indicated by the release of the sorbed OTC from soils into a slightly alkaline magnesium chloride solution. Their findings indicated that soil organic matter and clay are effective in the sorption of OTC and its potential availability. Jia et al (24) showed that the sorption of OTC on biochar depends highly on the $\mathrm{pH}$ of the solution. Their results also indicated the enhancement of sorption by the presence of $\mathrm{Cu}^{2+}$ ions. Conversely, the sorption of OTC showed a slight reduction when $\mathrm{Pb}^{2+}$ was present in acidic conditions.

In the present work, selected Passaic River sediment samples were used for the removal of OTC from water. The sorption capacity of such riverine sediments was correlated with the clay content, iron, and organic matter contents.

\section{Materials and Methods}

Apparatus

Pyrolysis GC-MS

All sediment samples were dried and milligram quantities were placed in the pyrolytic cell together with $5 \mu \mathrm{L}$ of a solution containing D-naphthalene, D-anthracene, and D-pyrene (Sigma Aldrich and Cambridge Isotope Laboratories). The spike concentration was manipulated such that each injection introduced $24.50 \mathrm{ng}$ of D-naphthalene and $27.00 \mathrm{ng}$ of $\mathrm{D}$-anthracene into the chromatographic system. D-pyrene was not used for quantization. A CDS model 1500 pyrolizer system was used to heat both the sediment and phragmites samples to $610^{\circ} \mathrm{C}$ for 20 seconds under a helium atmosphere. The GC column used for sediment analysis was $0.25 \mathrm{~mm}$ ID, $60 \mathrm{~m}$ in length, and packed with the dimethyl polysiloxane stationary phase (Restek catalog number 13326, Restek Chromatography, Bellefonte, PA) The GC column used for the phragmites analysis was an Agilent (J\&W) $30 \mathrm{~m}$, DB1-MS, $0.25 \mathrm{~mm}$ ID, (Agilent, catalog number 122-0132UI). The details of the GC temperature programs were described in detail elsewhere (25). Operating in full-scan mode, the mass spectrometer was set to 50-550 Da, 1.08 scans/s, and 70 $\mathrm{eV}$ ionization voltage. Peak identification was based on a combination of molecular weight and retention time window for each compound.

\section{HPLC analysis}

OTC concentrations were analyzed by high performance liquid chromatography (HPLC). The conditions and details of the analysis system are described elsewhere (14).

\section{Induced coupled plasma analysis}

The sediments $(0.50 \mathrm{~g})$ were extracted with $10 \mathrm{~mL}$ of 0.5 $\mathrm{M} \mathrm{HCl}$ for 2 hours in 50-mL centrifuge plastic tubes. The tube contents were centrifuged and filtered with a $0.2-\mu$ syringe microfilter. The filtrate was analyzed for iron using induced coupled plasma (ICP) optical emission spectrometry on an ICP-MS Thermo X-Series II, Thermo-Electron, San Hose, CT). The analysis was done in duplicate. The standard conditions recommended by the manufacturer were used. The results are given in Table 1.

\section{Materials and reagents}

OTC, $\mathrm{C}_{22} \mathrm{H}_{24} \mathrm{~N}_{2} \mathrm{O}_{9}$, and HPLC solvents used in this study were as described earlier (14). NanoPure water was used for the preparation and dilution of working solutions. Buffer solutions were prepared from Pipes, which is the common name for piperazine-N, N'-bis(2-ethanesulfonic acid) as described earlier (14).

\section{Sediments}

Seven sediment samples were used in this study, comprising 4 locations (5A, 7A, 9A, and 10A) and three different depths (26). Figure 1 shows a satellite image of the NY/NJ harbor estuary system with core locations. 
Table 1. The clay, organic (LOI\%) and extractable iron contents of the selected sediment samples

\begin{tabular}{lllll}
\hline Soil Code & Depth, cm & Clay content & $\begin{array}{l}\text { Organic content, } \\
\text { LOI, \% }\end{array}$ & Iron, \% \\
\hline 5A S38 & $330-340$ & 26.18 & 4.59 & 0.55 \\
5A S46 & $449-469.5$ & 3.15 & 4.02 & 0.235 \\
7A S34 & $435-450$ & 28.26 & 7.613 & 0.721 \\
9A S06 & $45-54$ & 7.29 & 8.49 & 0.601 \\
9A S34 & $547-566$ & 19.72 & 16.63 & 0.735 \\
10A S28 & $203-212$ & 20.93 & 13.03 & 0.666 \\
10A S46 & $365-375$ & 12.25 & 2.82 & 0.36 \\
\hline
\end{tabular}

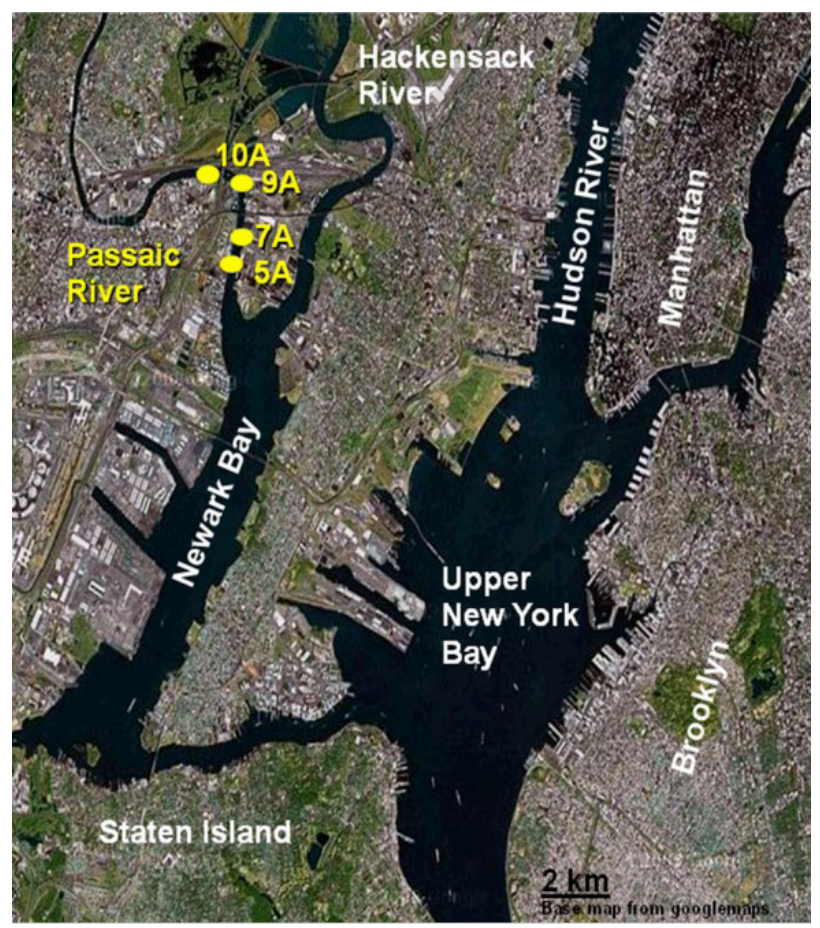

Figure 1. Satellite image of the NY/NJ harbor estuary system with core locations.

\section{Procedures}

\section{Sorption}

The sorption of OTC was carried out in 15-mL centrifuge tubes in the presence of two levels of sediment samples: $0.25 \mathrm{~g}$ and $0.5 \mathrm{~g}$. The procedures followed were previously fully described by Barbooti et al (14).

Organic matter content was determined using the losson-ignition (LOI) standard test in which the sample was weighed on an analytical balance before and after heating overnight at $400^{\circ} \mathrm{C}$. This temperature was recommended by the USEPA to prevent the destruction of carbonates and a resulting positive error (27).

\section{Removal of organic matter}

The organic matter of the sediments was removed by adding the sediment sample $(2.5 \mathrm{~g})$ into $50 \mathrm{~mL}$ of sodium hypochlorite solution at $\mathrm{pH} 12$ (28) with occasional swirling. Alternatively, $2.5 \mathrm{~g}$ sediments were treated with several volumes of hydrogen peroxide (29) and kept overnight with occasional swirling until the gas evolution ceased.
The materials were then washed several times with deionized water to remove any residual salt or excess oxidant.

Petroleum hydrocarbon determination

A sediment sample (1-5 g) was equilibrated with $10 \mathrm{~mL}$ of the solvent for 4 minutes and left to stand for one minute. The solution was decanted through a $0.2 \mu$ filter into a glass cell containing developer material at a ratio of $2: 3$ (hydrocarbon solution: developer solution), mixed for 20 seconds, and left to stand for 10 minutes. The resultant emulsion was quantitated by turbidimetry (30).

\section{Results}

Table 1 shows the clay contents, organic matter (measured as LOI\%), and extractable iron contents for the selected sediment samples. The clay contents of the sediments ranged 12\%-28\%, except for sample 5A S46 which had a relatively low clay content of $3.15 \%$. The LOI measurements indicated that the sediments were relatively rich with organic materials $(4 \%-16 \%)$ with the exception of sample 10A S46 which had the lowest LOI\% of $2.82 \%$. All sediment samples had an appreciable extractable iron content $(0.23 \%-0.72 \%)$.

The sediment samples were pyrolyzed at $600^{\circ} \mathrm{C}$ and the products were analyzed by GC. Some of the GC-pyrograms are shown in Figure 2. The signals related to plant materials resembled those given by reed powder sampled from Montclair, NJ (Figure 3). The characterization of
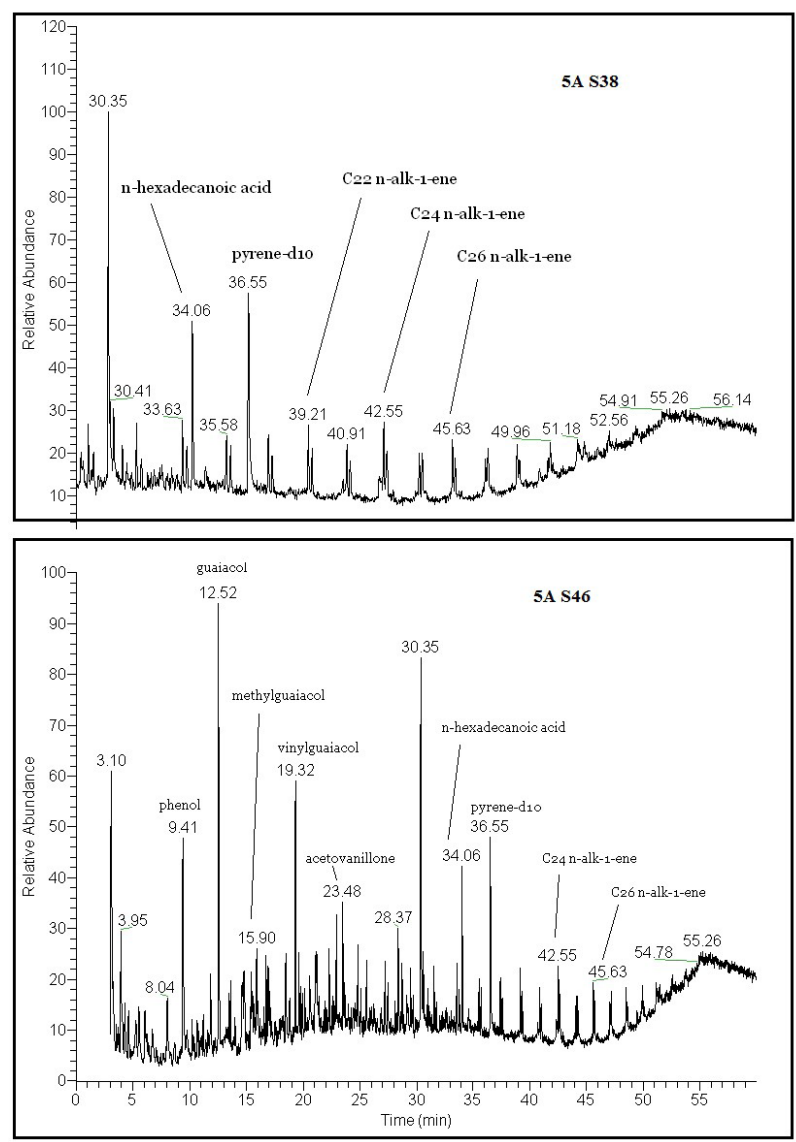

Figure 2. Py GC-MS of sediments 5A S38 and 5A S46. 
Table 2. Py GC-MS characterization of sediments organic matter, ng. $\mathrm{mg}^{-1}$

\begin{tabular}{|c|c|c|c|c|c|c|c|}
\hline \multirow{2}{*}{ Group compound } & \multicolumn{7}{|c|}{ Sediment } \\
\hline & $5 A 38$ & $5 A 46$ & $7 A 34$ & $9 A 06$ & 9A34 & $10 A 28$ & $10 \mathrm{~A} 46$ \\
\hline Total fatty acids & 9.49 & 0.23 & 0.56 & 1.29 & 1.87 & 3.46 & 0.24 \\
\hline Total angiosperm lignin markers & 0 & 7.26 & 1.07 & 9.06 & 2.51 & 0 & 0 \\
\hline Total lignin markers & 92.99 & 24.54 & 7.54 & 30.12 & 61.94 & 1.32 & 1.32 \\
\hline Total petroleum markers & 0 & 0 & 2.34 & 1.96 & 7.43 & 0.4 & 0.4 \\
\hline Total polysaccharide markers & 119.92 & 6.69 & 4.63 & 18.01 & 19.02 & 1.83 & 1.83 \\
\hline Total sewage markers & 0 & 0.03 & 0.24 & 0.12 & 3.1 & 0.16 & 0.16 \\
\hline Total sulfur compounds & 46.47 & 0.23 & 5.01 & 2.4 & 7.78 & 1.19 & 1.19 \\
\hline
\end{tabular}

each group was indicated by some marker compounds as given in Table 2. Figure 4 shows the pyrograms of one of the sediments after treatment with hydrogen peroxide displayed with that of the untreated sediments for comparison.

The extent of OTC sorption on the sediment samples for two levels of solid sorbent to water is indicated in Table 3. It appears that the extent of adsorption did not double when the soil contents in water were doubled. To account for the extent of OTC sorption on the Passaic sediments, the results were correlated with the various components. Clay materials were among the successful sorbents of the antibiotic, and hence, the correlation began with the clay contents of the sediments. A plot of the extent of OTC sorption against the clay contents of the soils under investigation is shown in Figure 5. The correlation coefficient $\left(\mathrm{R}^{2}\right)$ was 0.318 for $2.5 \mathrm{~g}$ soil $/ \mathrm{L}$ and 0.3036 for $5.0 \mathrm{~g}$ soil/L; the intercept was 32.7 .

The sorption efficiency of the sediment samples was correlated with the available iron content (Table 1 ), and the plot is shown in Figure 6. The sorption data were correlated with the LOI percentages as shown in Figure 7, and a linear plot with a correlation coefficient $\left(\mathrm{R}^{2}\right)$ of 0.7499 could be obtained, which indicates a direct relationship between OTC adsorption and organic matter content.

\section{Discussion}

\section{Organic Matter Characterization}

Sediment samples were analyzed with pyrolysis GC-Ms to identify and quantify organic compounds. Three categories of organic materials were identified in the pyrolyzed samples: petroleum hydrocarbons, anthropogenic materials, and plant residual materials (26). The chosen soil samples were characterized by biomass origin and hydrocarbon organic matter, which increases in the order of

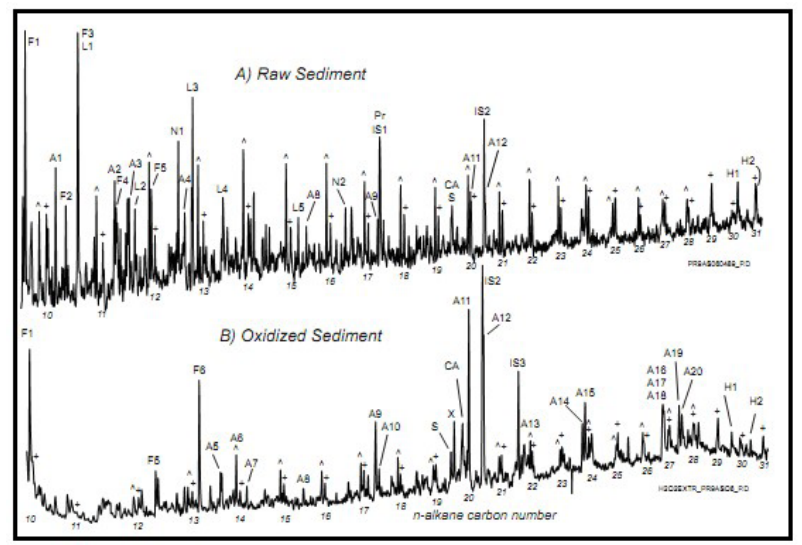

Figure 4. Py-GC of sediment $9 \mathrm{~A}(45-54 \mathrm{~cm}$ core depth): (A) before and $(B)$ after oxidation with hydrogen peroxide.

$5 \mathrm{~A}<7 \mathrm{~A}<9 \mathrm{~A}<10 \mathrm{~A}$ of the cores used in this study (31). The pyrogram of the sediments treated by hypochlorite exhibited only the base line and therefore indicated the complete removal of all types of organic matter. The $\mathrm{H}_{2} \mathrm{O}_{2}$ treatment resulted in the complete disappearance of the plant residues peaks (Figure 4). Meanwhile, the hydrogen peroxide treatment gave only a slight reduction in the peaks of petroleum hydrocarbons.

The plot of correlation of the adsorption capacity with the clay content of sediments (Figure 5) indicated only weak correlations for the clay contents in the suspension. Also, the intercept $=32.7$, indicative of the activity of other parameters on sorption and that clay is not the only factor in the determination of adsorption capacity. Thus, sediment parameters other than clay content are predominant in this respect. Comparable results were obtained by ThieleBruhn (1), who reported a correlation coefficient of 0.34 with the clay content of soil. Kasteel et al (18) reported

Table 3. The sorption of oxytetracycline in soil samples

\begin{tabular}{|c|c|c|c|c|}
\hline \multirow{2}{*}{ Soil code } & \multicolumn{2}{|c|}{ \% Sorbed antibiotic } & \multirow{2}{*}{$\begin{array}{c}\text { Cs, } \mathrm{mmol} / \mathrm{g} \\
5 \mathrm{~g}\end{array}$} & \multirow{2}{*}{$\begin{array}{c}\text { Cs, } \mathrm{mmol} / \mathrm{g} \\
2.5\end{array}$} \\
\hline & $2.5 \mathrm{~g}$ Soil/L & $5.0 \mathrm{~g}$ Soil/L & & \\
\hline $5 A$ S38 & $38.1 / 30.9$ & $50.2 / 20.1$ & 0.0402 & 0.1173 \\
\hline $5 \mathrm{~A} S 46$ & $30.2 / 24$ & $39.8 / 16$ & 0.0318 & 0.07682 \\
\hline 7A S34 & $47.0 / 37$ & $52.6 / 21$ & 0.0421 & 0.13305 \\
\hline 9A S06 & $43.9 / 35$ & $53.5 / 22$ & 0.0428 & 0.4815 \\
\hline 9A S34 & $52.2 / 41$ & $60.9 / 24$ & 0.0487 & 0.213 \\
\hline 10 A S28 & $59.5 / 48$ & $67.9 / 27$ & 0.0543 & 0.2274 \\
\hline $10 \mathrm{~A} S 46$ & $30.1 / 24$ & $38.8 / 15$ & 0.0310 & 0.1959 \\
\hline
\end{tabular}




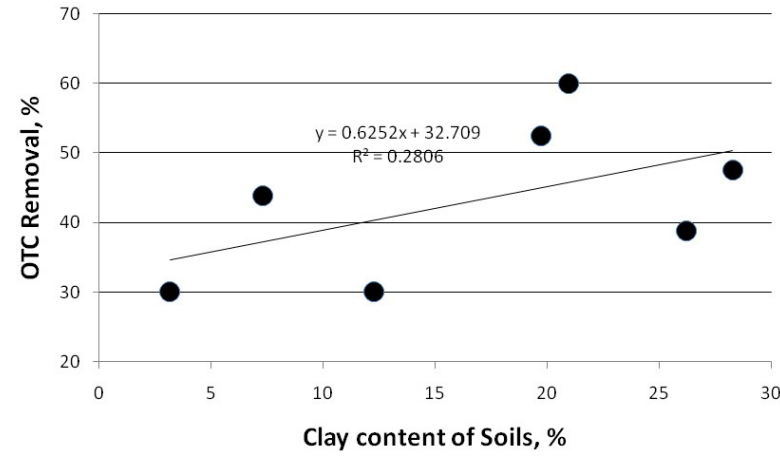

Figure 5. Correlation of adsorption capacity with clay content of Passaic sediments at $2 \mathrm{~g} / \mathrm{L}$ level.

that the sorption of antibiotics into soil was affected by the equilibration time and $\mathrm{pH}$ of the solution. A higher sorption capacity was reported for loamy sand.

The plot of the sorption capacity against the iron content of the sediments (Figure 6) showed a reasonable correlation with $\mathrm{R}^{2}$ values of 0.7499 and 0.7074 for 2.5 and $5.0 \mathrm{~g} / \mathrm{L}$ sediment samples, respectively. Thus, the sorption efficiency is linearly changing with the available iron content. The effect of organic matter on adsorption is shown in Figure 7 . The relatively high $\mathrm{R}^{2}$ of 0.7899 indicated a direct relationship of the OTC adsorption with the organic matter content of the soil samples studied. Pateiro-Moure et al (32) reported that the universal soil colloid that binds most herbicides is organic matter; however, metallic hydrous oxides might also have some influence. Soil texture, CEC, and iron oxide content seemed to have some influence on the extent of TC sorption in soils with an OC content between $0 \%$ and $4 \%$ (22). Residual concentrations of pharmaceutical antibiotics exert a temporary selective pressure on soil microorganisms, which is clearly influenced by soil adsorption (1).

Thus, the entire adsorption is associated with the organic compounds available in Passaic River sediments.

Natural organic matter in soils interacts with surfaces of inorganic materials, primarily aluminosilicates or clay minerals, to form a strongly associated organo-mineral composite known as humin. Upon removal of the organic matter from the soils, surface area increased and surface pore size decreased (33). This may account for the slight change in the sorption properties of the Passaic sediments after the organic matter was removed.

MacKay and Canterbury (21) referred the enhanced sorption of OTC into soils rich with organic matter to the formation of complexes. This applies to the soil samples in this study where low clay content samples showed considerable OTC sorption due to the occurrence of organic matter.

Antibiotics may appear in the environment when manure, sewage sludge, or other organic amendments are added to soils. The sorption of chlortetracycline (CTC) and tylosin in sandy loam and clay occurs very fast. More than $95 \%$ of the CTC adsorption is completed within 10 minutes on both soils and of TYL within 3 hours (20). When they

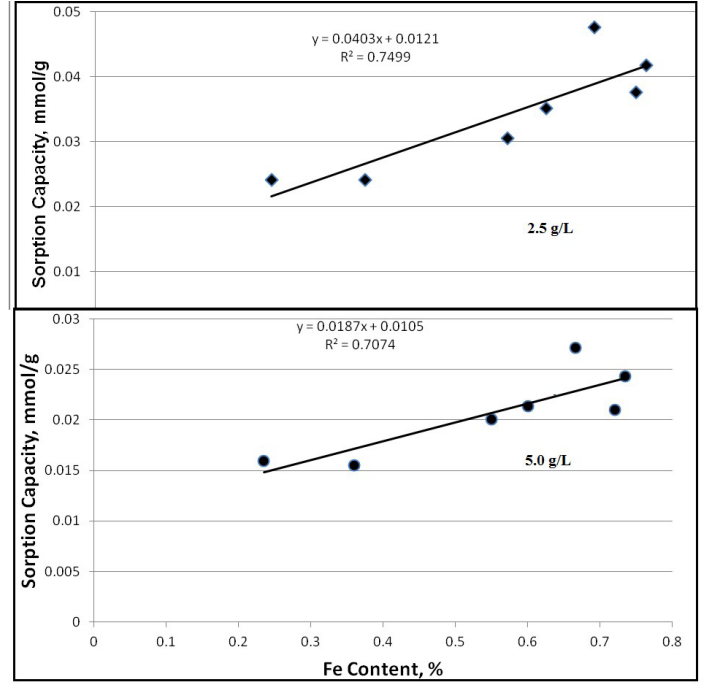

Figure 6. Effect of available iron content of sediments on sorption efficiency for $2.5 \mathrm{~g} / \mathrm{L}$ and $5 \mathrm{~g} / \mathrm{L}$ levels.

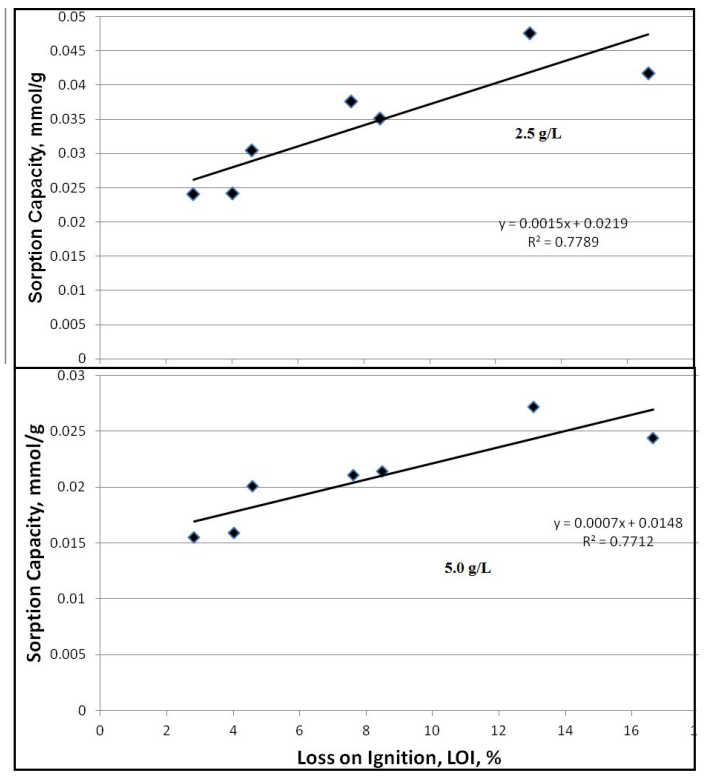

Figure 7. Dependence of adsorption capacity on the organic matter of soil (Loss on Ignition) for $5 \mathrm{~g} / \mathrm{L}$.

interpreted the sorption of OTC onto marine sediments, Pouliquen and Le Bris (34) concluded that sorption increased with sediment content in mineral and organic matter and in particles of less than $63 \mu \mathrm{m}$ in diameter.

\section{Conclusion}

Pyrolysis GC-MS and spectrophotometric measurements may be used to investigate the role of organic matter and iron in the interaction of OTC with river sediments. The organic matter of sediments has petroleum, plant, and anthropological origins. Non-petroleum organic matter is effective and has a direct relationship with the sorption capacity of the sediments. To a lesser extent, iron content is effective in determining sediment sorption capacity. Although clay materials are active sorbents for OTC, the presence of organic matter reduces such activity. 


\section{Acknowledgments}

This work was carried out during a sabbatical leave at Montclair State University, New Jersey and financially supported by the International Institute of Education, IIE. The author is grateful to Prof. D. Sarkar, Prof M. Kruge, Dr. K. Olsen, and Dr. P. Punimaya from Montclair State University for their help during the practical work and the valuable discussions.

\section{Ethical issues}

The author hereby certifies that all data collected during the study is as stated in the manuscript, and no data from the study has been or will be published separately elsewhere.

\section{Competing interests}

The author declares that he has no competing interests.

\section{Author's contribution}

MMB is the single author of the paper.

\section{References}

1. Thiele-Bruhn S. Pharmaceutical antibiotic compounds in soils—a review. J Plant Nutr Soil Sci 2003; 166(2): 145-67. doi: $10.1002 /$ jpln.200390023.

2. Kroker R. Aspects of the elimination of antibiotics after treatment of domestic animals. Wissenschaft Umwelt 1983; 4: 305-08.

3. Küster A, Alder AC, Escher BI, Duis K, Fenner K, Garric J, et al. Environmental risk assessment of human pharmaceuticals in the European Union: A case study with the $\beta$-blocker atenolol. Integr Environ Assess Manag 2010; 6(suppl 1): 514-23. doi: 10.1897/IEAM_2009-050.1.

4. Batt AL, Kim S, Aga DS. Comparison of the occurrence of antibiotics in four full-scale wastewater treatment plants with varying designs and operations. Chemosphere 2007; 68(3): 428-35 doi: 10.1016/j.chemosphere.2007.01.008.

5. Huysman F, van Renterghem B, Verstraete W. Antibiotic resistant sulfite-reducing Clostridia in soil and groundwater as indicator of manuring practices. Water Air Soil Pollut 1993; 69(3): 243-55. doi: 10.1007/BF00478161.

6. Fründ HC, Schlösser A, Westendarp H. Effects of tetracycline on the soil microflora determined with microtiter plates and respiration measurement. Mitteilgn Dtsch Bodenkundl Gesellsch 2000; 93: 244-7.

7. Wehrhan A, Kasteel R, Simunek J, Groeneweg J, Vereecken $\mathrm{H}$. Transport of sulfadiazine in soil columns - experiments and modelling approaches. J Contam Hydrol 2007; 89(1-2): 107-35. doi: 10.1016/j.jconhyd.2006.08.002.

8. Hamscher G, Sczesny S, Höper H, Nau H. Determination of persistent tetracycline residues in soil fertilized with liquid manure by high-performance liquid chromatography with electrospray ionization tandem mass spectrometry. Anal Chem 2002; 74(7): 1509-18. doi: 10.1021/ac015588m.

9. Hoper H, Kues J, Nau H, Hamscher G. Eintrag und Verbleib von Tierarzneimittelwirkstoffen in Boden. Bodenschutz 2002; 7(4): 141-8.

10. Shi H, Yang Y, Liu M, Yan C, Yue H, Zhou J. Occurrence and distribution of antibiotics in the surface sediments of the Yangtze Estuary and nearby coastal areas. Mar Pollut Bull 2014; 83(1): 317-23. doi: 10.1016/j.marpolbul.2014.04.034.
11. Liu X, Zhang H, Li L, Fu C, Tu C, Huang Y, et al. Levels, distributions and sources of veterinary antibiotics in the sediments of the Bohai Sea in China and surrounding estuaries. Mar Polluut Bull 2016; 109(1): 597-602. doi: 10.1016/j.marpolbul.2016.05.033.

12. Pils JRV, Laird DA. Sorption of Tetracycline and chlortetracycline on K- and Ca-saturated soil clays, humic substances, and clay-humic complexes. Environ Sci Technol 2007; 41(6): 1928-33. doi: 10.1021/es062316y

13. Zhang Z, Sun K, Gao B, Zhang G, Liu X, Zhao Y. Adsorption of tetracycline on soil and sediment: effects of $\mathrm{pH}$ and the presence of $\mathrm{Cu}(\mathrm{II})$. J Hazard Mater 2011; 190(1-3): 856-62. doi: 10.1016/j.jhazmat.2011.04.017.

14. Barbooti MM, Su H, Punamiya P, Sarkar D. Oxytetracycline sorption onto Iraqi montmorillonite. Int J Environ Sci Technol 2014; 11(1): 69-76. doi: 10.1007/s13762-013-03616

15. Bezza FA, Nkhalambayausi-Chirwa EM. Desorption kinetics of polycyclic aromatic hydrocarbons (PAHs) from contaminated soil and the effect of biosurfactant supplementation on the rapidly desorbing fractions. Biotechnol Biotechnol Equip 2015; 29(4): 680-88. doi: 10.1080/13102818.2015.1028444.

16. Kordel W, Dassenakis M, Lintelmann J, Padberg S. The importance of natural organic material for environmental processes in waters and soils. Pure and Applied Chemistry 1997; 69(7): 1571-600.

17. Shareef KM, Ahmed HO. Thermodynamics of equilibrium adsorption of antibiotics at olid-liquid interface. Proceedings of the 2nd International Conference on Maritime and Naval Science and Engineering; Sep 24-26, 2009; Transilvania University of Brasov, Romania; 2009.

18. Kasteel R, Mboh CM, Unold M, Groeneweg J, Vanderborght J, Vereecken H. Transformation and sorption of the veterinary antibiotic sulfadiazine in two soils: a short-term batch study. Environ Sci Technol 2010; 44(12): 4651-7. doi: $10.1021 / \mathrm{es} 100141 \mathrm{~m}$.

19. Li J, Zhang H. Adsorption-desorption of oxytetracycline on marine sediments: Kinetics and influencing factors. Chemosphere 2016; 164: 156-63. doi: 10.1016/j. chemosphere.2016.08.100.

20. Allaire SE, Del Castillo J, Juneau V. Sorption kinetics of chlortetracyline and tylosin on sandy loam and heavy clay soils. J Environ Qual 2005; 35(4): 969-972. doi: 10.2134/ jeq2005.0355.

21. MacKay AA, Canterbury B. Oxytetracycline sorption to organic matter by metal-bridging. J Environ Qual 2005; 34(6): 1964-71. doi: 10.2134/jeq2005.0014.

22. Jones AD, Bruland GL, Agrawal SG, Vasudevan D. Factors influencing the sorption of oxytetracycline to soil. Environ Toxicol Chem 2005; 24(4): 761-70.

23. Kong W, Li C, Dolhi JM, Li S, He J, Qiao M. Characteristics of oxytetracycline sorption and potential bioavailability in soils with various physical-chemical properties. Chemosphere. 2012; 87(5): 542-8. doi: 10.1016/j. chemosphere.2011.12.062.

24. Jia M, Wang F, Bian Y, Jin X, Song Y, Kengara FO, et al. Effects of $\mathrm{pH}$ and metal ions on oxytetracycline sorption to maize-straw-derived biochar. Bioresource Technol 2013; 136: 87-93. doi: 10.1016/j.biortech.2013.02.098.

25. Olsen K. Organic geochemical investigations of urban sediments by pyrolysis-Gas chromatography/mass spectroscopy [dissertation]. Montclair, NJ: Montclair State 
University; 2014.

26. Bujalski NM, Kruge MA. Characterization of contaminant and biomass-derived organic matter in sediments from the Lower Passaic River, New Jersey, USA [dissertation]. Montclair, NJ: Montclair State University; 2010.

27. Schumacher BA. Methods for the determination of total organic carbon (TOC) in soils and sediments. Washington, DC: U.S. Environmental Protection Agency; 2002.

28. Siregar A, Kleber M, Mikutta R, Jahn R. Sodium hypochlorite oxidation reduces soil organic matter concentrations without affecting inorganic soil constituents. Eur J Soil Sci 2005; 56(4): 481-90. doi: 10.1111/j.1365-2389.2004.00680.x.

29. Mikutta R, Kleber M, Kaiser K, Jahn R. Organic matter removal from soil using hydrogen peroxide, sodium hypochlorite, and disodium peroxodisulfate. Soil Sci Soc Am J. 2005; 69(1): 120-35. doi: 10.2136/sssaj2005.0120.

30. Barbooti MM. Turbidimetric determination of hydrocarbon contamination in Passaic River sediments and refinery polluted soils. J Environ Prot 2011; 2(7): 915-22. doi: 10.4236/jep.2011.27104.

31. Micić V, Kruge MA, Köster J, Hofmann T. Natural, anthropogenic and fossil organic matter in river sediments and suspended particulate matter: a multi-molecular marker approach. Sci Total Environ 2011; 409(5): 905-19. doi: $\quad 10.1016 /$ j.scitotenv.2010.11.009.

32. Pateiro-Moure M, Pérez-Novo C, Arias-Estévez M, RialOtero R, Simal-Gándara J. Effect of organic matter and iron oxides on quaternary herbicide sorption-desorption in vineyard-devoted soils. J Colloid Interface Sci 2009; 333: 431-8. doi: 10.1016/j.jcis.2009.02.019.

33. Malekani K, Rice JA, Lin JS. The effect of sequential removal of organic matter on the surface morphology of humin. Soil Sci 1997; 162(5): 333-42.

34. Pouliquen $H$, Le Bris $H$. Sorption of oxolinic acid and oxytetracycline to marine sediments. Chemosphere 1996; 33(5): 801-15. 